\title{
La barbarie entre la minucia y la alegoría: Diario de la guerra del cerdo, de Adolfo Bioy Casares
}

\author{
Barbarism between the minutia and allegory. Diario de \\ la guerra del cerdo, of Adolfo Bioy Casares \\ Barbárie entre a minúcia e alegoria. Diario de la \\ guerra del cerdo, Adolfo Bioy Casares
}

\section{Elisa Calabrese}

UNIVERSIDAD NACIONAL DE MAR DEL PLATA, ARGENTINA

Profesora titular en el área de Literatura Argentina de la carrera de Letras de la Universidad Nacional de Mar del Plata, Argentina. Profesora extraordinaria en la categoría emérita por la misma universidad, desde 2009. Doctora en Letras por la Universidad de Buenos Aires, Argentina. Ha publicado numerosos artículos en revistas especializadas y entre sus últimos libros pueden citarse: Animales fabulosos.

Las revistas de Abelardo Castillo, en colaboración con Aymará de Llano (Editorial Martín, 2006), Lugar común. Lecturas críticas de literatura argentina (EUDEM, 2009) y Sábato. Historia y apocalipsis

(Alción, 2013). Correo electrónico: eliscalabrese@gmail.com 


\section{Resumen}

Si bien Adolfo Bioy Casares es reconocido unánimemente como un narrador importante, su novela Diario de la guerra del cerdo (1969) no ha concitado la atención de la crítica de modo comparable a otras ficciones del autor. Este trabajo postula la hipótesis de la existencia de una tradición alegórica en la literatura argentina moderna, al considerar Diario... una de las ficciones centrales de esa corriente, que si bien se desvía del realismo, no podría ser leída como fantástica. Con ese fin, se expone una lectura política del texto para mostrar cómo en este se puede explorar una singular construcción de la barbarie ubicada en el peronismo.

Palabras clave: alegoría; conflicto generacional; política; barbarie; peronismo; Adolfo Bioy Casares; literatura argentina

\section{Abstract}

While Adolfo Bioy Casares is unanimously recognized as an important narrator, his novel Diario de la guerra del cerdo (1969) has not attracted the critical attention as other of their fictions has. This paper postulates the existence of an allegorical tradition in argentine modern literature and consider this novel one of the central fictions of that stream, because, although it's far from realism, could not be read as a fantastic narration. To prove this statement, this essay exposed a political reading of the novel to show how it explore a unique construction of barbarism located in Peronism.

Keywords: allegory; generational conflict; politics; Peronism ;

\section{Resumo}

Enquanto Adolfo Bioy Casares é unánimemente reconhecido como um narrador importante, seu romance Diario de la guerra del cerdo (1969), não tem atraído a atenção da crítica comparável a outros modo de ficções autor. Este trabalho postula a hipótese da existência de uma tradição alegórica na literatura moderna Argentina, considerando Diario... uma das ficções centrais desse fluxo, mas se afasta do realismo, pode ser lido como fantástica. Para o efeito, expôsum a leitura política do texto para mostrar como este pode explorar uma construção única da barbárie localizado no peronismo.

Palavras-chave: alegoria; política; barbárie; peronismo; Adolfo Bioy Casares; literatura Argentina

RECIBIDO: 10 DE OCTUBRE DE 2015. ACEPTADO: 11 DE NOVIEMBRE DE 2015. DISPONIBLE EN LÍNEA: 1 DE JULIO DE 2016

\section{Cómo citar este artículo:}

Calabrese, Elista T. "La barbarie entre la minucia y la alegoría: Diario de la guerra del cerdo, de Adolfo Bioy Casares". Cuadernos de Literatura 20.40 (2016): 560-568. http://dx.doi.org/10.11144/Javeriana.cl20-40.bmad 
EN 2014 SE celebró el centenario del nacimiento de célebres escritores latinoamericanos - Julio Cortázar, Octavio Paz, Efraín Huerta, José Revueltas y Nicanor Parra - entre los que se encuentra Adolfo Bioy Casares, a cuya novela Diario de la guerra del cerdo (1969) se dedican estas líneas. Si bien es unánime el reconocimiento por parte de la crítica de las cualidades narrativas de las ficciones de Bioy, considerado uno de los escritores pioneros de lo que se llamó "nueva novela" latinoamericana, esta en particular, a diferencia de La invención de Morel o El sueño de los héroes, no ha sido objeto de abundante indagación crítica. Desde mi perspectiva, se trata de una de las más complejas narraciones del autor, pues permite explorar la signatura política de una singular figuración de la barbarie, emplazada en el peronismo como significante por antonomasia de la moderna encarnación de la dicotomía sarmientina. Como suele ocurrir cuando la lectura crítica requiere un apoyo por parte de la reflexión teórica, Borges nos provee, con pocas frases, de lo necesario. Si bien es excepcional que no haya dejado escrita su lectura de este texto en particular de su amigo, sí lo hizo, como es sabido, con sus muy conocidos prólogos a otras novelas de Bioy. Así, refiriéndose a El sueño de los héroes, Borges destaca como méritos del relato su "estilo oral" y "su trama onírica"; pero afirma preferir "su valor como símbolo", pues "la amarga y lúcida versión" de nuestra historia argentina ideada por Bioy le parece corresponder perfectamente a "estos años que corren" ("Adolfo Bioy" 285). Tomando en cuenta que la novela se publica en 1954 y su reseña aparece en julio de 1955 en $S U R$, cuando aún no había acontecido el golpe que derrocó a Perón en septiembre de ese año, es evidente que Borges reconoce dos condiciones esenciales de la narrativa de Bioy que, en rigor, se aúnan en una sola y sin duda reaparecen, intensificadas, en Diario...: su índole alegórica y la dirección política de su trayectoria de sentido. Una aclaración importante para el planteo donde ancla este trabajo es que Borges llama indistintamente "símbolo" o "alegoría" a esta última, como se puede ver cuando escribe: "Los símbolos además del valor representativo tienen un valor intrínseco...", aseveración para la cual ofrece ejemplos tan abundantes como claros. Baste citar uno: "La hambrienta y flaca loba del primer canto de la Divina Comedia no es un emblema o letra de la avaricia: es una loba y es también la avaricia, como en los sueños" ("Sobre una" 200-203). Por su parte, en El origen del drama barroco alemán, Walter Benjamin reflexiona acerca de las similitudes entre ciertos textos del siglo XVII con la formación de la historia alemana, relación que se hace posible a partir del concepto que el filósofo designa como alegoría. El libro sobre el Barroco la estudia desde una perspectiva teológica que describe la alegoría como modo de expresión de una época de desalojo de lo divino, de secularización y de descomposición del 
sentido, que opone así el símbolo (o alegoría medieval) a la alegoría barroca. Si la primera, de procedencia cristiana, tuvo el impulso edificante de transparentar en el marco de la ortodoxia religiosa, un concepto moral o metafísico a través de una imagen, la segunda, de raíces antiguas (egipcias y griegas), resplandece en el Barroco con un carácter enigmático y críptico, al desplazar toda pretensión de transparencia edificante. Así, Benjamin buscará ir más allá de aquella concepción clásica de la "alegoría-signo", para liberar la alegoría a sus posibilidades autónomas, como forma singular de la experiencia del lenguaje y del mundo, no medieval sino ya moderna, decididamente anticlásica. Si el símbolo representaba la posibilidad del hombre de encontrar aquello que lo trascendiera, la alegoría sería la desarticulación de toda unidad, donde se extingue esa falsa apariencia de totalidad. Este mínimo rodeo teórico habilita para entender más en profundidad cómo Borges detecta el carácter alegórico de la trama onírica de El sueño de los héroes, al referirlo a la historia de su presente, impregnado por el peronismo; entonces, podré hacer extensiva esa condición a Diario... pues es también propio de ella la índole peculiar de su atmósfera, donde conviven la lucidez del detalle microscópico con la pesadilla, pero ambos inmersos en una estructura narrativa simple a la vez que tensa, plasmada en una escritura oscilante entre la minuciosa escenificación de la vida cotidiana y aquello que la excede. De este modo, el verosímil narrativo se desvía de la representación realista, debido a la constante presencia de lo ominoso por innominado, aunque no podamos atribuirle en plenitud el estatuto de lo fantástico.

La historia es simple, presentada a la manera de un diario, con una sola entrada fechada en día y mes -25 de junio - aunque sin especificación del año -lo cual, como aspiro a mostrar, tiene importancia- y narra la persecución, el hostigamiento y, a veces, la muerte con que grupos de jóvenes atacan con violencia desatada a los viejos, sin que sepamos claramente - ni los lectores ni el protagonista, Vidal- cuál podría ser el motivo. Flota desde el comienzo una suerte de repulsión indiscriminada hacia los ancianos que traduce con intensidad despiadada los imaginarios de la sociedad moderna occidental respecto de la vejez, etapa cronobiológica final de la existencia humana, por lo que se la metaforiza como el otoño de la vida. Quienes la transitan suelen presentar signos corporales que los identifican - canas y arrugas - como muestras evidentes del paso del tiempo, además de responder a identidades generacionales cuyos valores epocales son más próximos al pasado que al presente; de allí que se los arrincone en un espacio social de bordes o márgenes. De este modo, en el combate entre generaciones, se los convierte en sujetos en diáspora de los lugares de sociabilidad y de poder vulnerando su condición de sujetos de derecho, afecciones y pasiones. Mientras en ciertas culturas los ancianos funcionan como un auténtico "sostén 
de la cultura", en cuanto trasmisores de experiencia a las cohortes de jóvenes, en la nuestra, los adultos mayores son considerados poseedores de saberes y destrezas obsoletos. Por ende, es una consecuencia esperable que se comporten como una anticultura, pues en lugar de ostentar los atributos que los definen, tratan de ocultarlos para parecer más jóvenes, con el afán de ser aceptados y no caer en el espacio de la marginación. Desde la mirada de los otros, los viejos son envueltos en un manto de negatividad, a quienes les atribuyen declinación, obsolescencia, basadas en el imaginario cultural de anacronía; abyección, debido al imaginario estético que abomina de la decrepitud; silencio, por el anatema sobre quien se supone no tiene nada que decir, y desesperanza, debido a la pérdida de la energía vital, pero especialmente se los sanciona con un tabú sobre su erotismo, pues dadas esas condiciones de posibilidad, la consecuencia esperada es que el amor les esté vedado y apagada totalmente la pasión. Esto último es quizá un posible motivo de los ataques, pues se diseminan en el texto calificativos como "los viejos asquerosos", que aluden a la seducción por parte de los longevos hacia las muchachas jóvenes para sus goces abyectos. Así, la figura del cerdo, emblema de barbarie voluptuosa, se opone a la del búho, representante de un imaginario de serena reflexión y predominio de la comprensión intelectual, inscrito en el linaje mítico del búho de Minerva, figuración de la vejez como sabiduría, lejana a los placeres de la carne.

Sin embargo, las alegorías del relato son complejas y lejos de asumir un sentido monovalente - recordemos las observaciones de Borges- están atravesadas por la parodia y sutil ironía de la escritura de Bioy. El relato, situado en el punto de vista de Vidal, hombre gris y tímido, habitante de una pensión, quien ha criado solo a su hijo, pues su mujer lo abandonó hace ya muchos años, nos deja apreciar que él mismo comparte todos esos estigmas del imaginario sobre la vejez, pues constantemente está observándose para advertir los avances de la decrepitud, como lo expone el episodio, ya al inicio del relato, de la pérdida de sus dientes; la extracción y la consecuente colocación de una dentadura postiza es experimentada por él no solo con dolor, sino con humillación. La sociabilidad de Vidal se limita a un grupo de amigos - Jimi, Néstor, Dante Rébora, Leandro Rey, Lucio Arévalo- con quienes juega al truco en un café cercano: la ironía de la escritura es igualmente impiadosa con todos ellos: "La vida social es el mejor báculo para avanzar por la edad y los achaques" (16), pontifica el texto que, por otra parte, es particularmente cruel con las mujeres: por ejemplo, todo el grupo desdeña a una señora mayor que al entrar al café dejó la puerta abierta. Ella se describe así: "por poco tropezó con una mujer vieja, flaca, estrafalaria, una viviente prueba de lo que dice Jimi: ‘ ‘La imaginación de la vejez para 
inventar fealdades!'” (14). Cada uno de los integrantes del grupo se destaca por alguna característica desagradable; completan así un panorama donde los viejos son feos, sucios, avaros, egoístas, aunque se autodenominen, con el tradicional eufemismo coloquial, "los muchachos": "El término muchachos, empleado por ellos, no supone un complicado y subconsciente propósito de pasar por jóvenes, como asegura Isidorito, el hijo de Vidal, sino que obedece a la casualidad de que alguna vez lo fueron..." (11).

El escepticismo y la desesperanza han socavado en Vidal toda creencia en la posible comunicación genuina o solidaridad de los demás; por ello, pese a tratar desde hace ya muchos años a sus compañeros de juego, tiene de sus amigos un conocimiento deficiente que los sucesos de esa semana de matanzas se encargarán de ir completando parcialmente: por ejemplo, es testigo de los perversos hábitos sexuales de uno de ellos. El texto se encarga de hacernos notar la descreencia en la amistad: "todos ellos [...] en la mesa de truco mataban el tiempo, lo pasaban bien, no porque se entendieran o congeniaran particularmente, sino por obra y gracia de la costumbre" (12). Pero, tal como anuncié al comienzo, es hora de ver cómo esta novela construye una de las más nítidas alegorías aptas para la lectura política que podamos hallar entre los escritos de Bioy. Llama la atención la falta de interés crítico en ella, cuando han sido trabajadas hasta el cansancio las parodias del peronismo en los llamados textos en colaboración, escritos junto con Borges. ¿Será, como supone agudamente María Teresa Gramuglio, que el peso autoral del nombre de Borges arrastra el de Bioy quien queda automáticamente sumido en esa poderosa corriente?

Sea como fuere, no insistiré en lo tantas veces señalado: esa constelación de atribuciones de la cultura argentina de élite que tenía la civilización inglesa como modelo, en contraste con lo popular, donde la dicotomía sarmientina encarna, tanto en la política como en la cultura, en las figuras del cabecita negra, de los descamisados peronistas y de su líder (Svampa). Pero no son estos ideologemas lo único que explica el rechazo al peronismo; recordemos que - tal como lo hace patente "La fiesta del monstruo" y otros ejemplos del mismo Borges- para ambos escritores el peronismo es una versión local del fascismo, sistema político e ideología de los que abominan, así como se posicionaron siempre contrarios a los gobiernos de facto y al militarismo nacionalista, cuyo lenguaje se parodia hasta la exasperación en algunos de los textos en colaboración, como es el caso de $U n$ modelo para la muerte (Calabrese). Desde las primeras páginas, se condensan las significaciones encriptadas por la alegoría, más complejas aún por el uso de la parodia. Veamos este inicio, cuando Vidal echa de menos su aparato de radio porque está descompuesto: 
Privado de ese vetusto artefacto, Vidal echaba de menos las cotidianas "charlas de fogón" de un tal Farrell, a quien la opinión señalaba como secreto jefe de los Jóvenes Turcos, movimiento que brilló como una estrella fugaz en nuestra larga noche política. Ante los amigos, que abominaban de Farrell, lo defendía, siquiera con tibieza; [...] reconocía en él y en todos los demagogos el mérito de conferir conciencia de la propia dignidad a millones de parias. (9-10)

No hace falta demasiada sutileza para reconocer el apellido del que fuera segundo presidente de facto (luego del general Ramírez) del golpe de Estado de 1943; el apodo de "jóvenes turcos" alude a su condición de militares del ala más nacionalista del Ejército, fundadora del Grupo de Oficinales Unidos (GOU), gestor de dicho golpe. En la realidad histórica, esos jóvenes turcos fueron también militares nacionalistas cuyos líderes tomaron el poder en Turquía al derrocar al sultán, a principios del siglo XX. Durante su gobierno, perpetraron el genocidio armenio en el cual se calcula que fueron ultimados un millón y medio de personas. Como se ve, la comparación no puede ser menos halagüeña, pero la alusión a Perón también se deja entrever, no solamente por el plural "todos los demagogos", sino porque él formó parte del gobierno de Farrell como secretario de Trabajo y Previsión, posición que fue su laboratorio de operaciones con los sindicatos, sector fundamental para su poder y promotor del mítico acontecimiento fundacional del peronismo: el 17 de octubre. Se refiere a eso la mención al efecto que la prédica del líder tuvo sobre las clases obreras: "millones de parias". Hay más, pues el título mismo de la novela depara sorpresas. En efecto, un conflicto homónimo se desarrolló en 1859, en las Islas San Juan, ubicadas entre la isla de Vancouver y la parte continental de Norteamérica. A raíz de una controversia doméstica entre vecinos que alcanzó ribetes inusitados, Estados Unidos y Gran Bretaña se enfrentaron en lo que se denominó la Guerra del Cerdo. El hecho puntual se desencadena, porque un gran cerdo negro, cuyo propietario era británico, invadió la huerta de un ciudadano estadounidense y devoró sus papas. El damnificado respondió con disparos y mató al animal. Al no ponerse de acuerdo las partes litigantes por la indemnización, se generó un conflicto internacional que culminó tras un arbitraje alemán, con la cesión de las Islas San Juan a Estados Unidos. Si la alegoría sigue dinamizando esta lectura al activar una cadena de sentidos, ¿cómo no recordar que fue en un evento destinado a reunir fondos para las víctimas del terremoto de San Juan donde se conocieron Perón y Eva Duarte? El magma de significaciones de la historia política argentina y sus figuraciones emblemáticas entre lo viejo de la tradición liberal y lo nuevo del peronismo, así como la lucha por el poder de las vanguardias esclarecidas de los jóvenes que emergen como un 
nuevo factor de gran empuje, se entreteje en el tapiz de la escritura de Bioy Casares. Por eso creo entrever como eficaz estrategia el no fechar el año de la entrada del diario, pues en cuanto la alegoría mira al pasado, podemos pensar en el GOU y los inicios del peronismo, el nacionalismo militar de derecha, los primeros sindicatos. En cambio, si recorremos con Vidal las calles del Buenos Aires de la guerra del cerdo considerando la fecha de publicación de la novela, 1969, vemos otras cosas: los jóvenes insurgentes, las explosiones aisladas cuyo eco se escucha a cada tanto; si asistimos a la conversación de Vidal con el joven taxista, donde este defiende la idea de que el fin justifica los medios al decir: "Porque si la gente pusiera en un platillo los resultados buenos y en otro la destrucción y el dolor, es decir, los malos, nunca habría una guerra ni una revolución" (199), pensaríamos, con justicia, en otro contexto. Recordemos el Mayo francés, cuyos efectos irradiaron mucho tiempo después de haber cesado su accionar, también la enorme influencia del sartrismo en los jóvenes intelectuales argentinos, las vanguardias esclarecidas, políticamente revolucionarias, que dejarán profundas huellas de su paso en la década que está por iniciarse y el ala izquierda combativa - formada, mayoritariamente por jóvenes - que, conocida con el nombre de la Tendencia, luchaba con el sector más tradicional y conservador del peronismo, aunque no lograron imponer su hegemonía dentro del movimiento: así, la alegoría se torna hacia el futuro. La égida de los búhos, por su parte, lleva a recordar la fuga de cerebros, acontecida en el país luego de la llamada "noche de los bastones largos" de 1966; otra dictadura militar, esta vez la de Onganía y la inauguración de la entrada represiva de la policía en la universidad. En síntesis: como el ángel de la historia de Benjamin, la alegoría de Bioy mira hacia dos direcciones opuestas, porque en ambas está el peronismo; ¿el viejo orden o el advenimiento del nuevo? Para Bioy Casares, en todo caso, es el caos, las ruinas de la historia.

\section{Obras citadas}

Benjamin, Walter. El origen del drama barroco alemán. Trad.José

Muñoz Millanes. Madrid: Taurus, 1980. Impreso.

Bioy Casares, Adolfo. Diario de la guerra del cerdo. Buenos Aires: Emecé, 1969. Impreso.

Borges, Jorge Luis. "Adolfo Bioy Casares: El sueño de los héroes". Borges

en Sur. Buenos Aires: Emecé, 1999. 284-286. Impreso.

Borges, Jorge Luis. "Sobre una alegoría china". Borges en Sur.

Buenos Aires: Emecé, 2001. 200-203. Impreso.

Calabrese, Elisa. "Escribir la barbarie argentina: una genealogía literaria de

Sarmiento a Saccomanno". Iberoamericana 17 (2005): 41-54. Impreso. 
De Toro, Alfonso y Regazzoni, Susana, eds. Homenaje a Adolfo Bioy Casares: una retrospectiva de su obra. Madrid: Iberoamericana, 2002. Impreso.

Geamuglio, María Teresa. "Bioy, Borges y Sur: diálogos y duelos". Anthropos (Barcelona) 127 (dic 1991): 65-73. Web.

Svampa, Maristella. El dilema argentino: civilización o barbarie. Buenos Aires: Taurus, 2006. Impreso. 